\title{
Intensive Care Unit Capacity and Its Associated Risk Factors During the COVID-19 Surge in the Republic of Korea: Analysis Using Nationwide Health Claims Data
}

This article was published in the following Dove Press journal:

Risk Management and Healthcare Policy

Seung Heon Lee, (D)' So-Youn Park, ${ }^{2}$ Jeong-Yeon Seon, (ID) ${ }^{3}$ Woo-Hwi Jeon, ${ }^{3}$ Sung-II Nam, ${ }^{4}$ Jong-Hak Park, ${ }^{5}$ Jae Seok Park, ${ }^{6}$ Hae-Young Kim, ${ }^{7}$ Niket Thakkar, ${ }^{8}$ Prashanth Selvaraj, ${ }^{8}$ Anna Bershteyn, (D) In-Hwan $\mathrm{Oh}^{3}$

'Division of Pulmonary, Sleep, and Critical Care Medicine, Department of Internal Medicine, Korea University Ansan Hospital, Ansan, Republic of Korea; ${ }^{2}$ Department of Medical Education and Humanities, School of Medicine, Kyung Hee University, Seoul, Republic of Korea; ${ }^{3}$ Department of Preventive Medicine, School of Medicine, Kyung Hee University, Seoul, Republic of Korea; ${ }^{4}$ Department of OtolaryngologyHead \& Neck Surgery, Keimyung University Dongsan Hospital, Keimyung University School of Medicine, Daegu, Republic of Korea; ${ }^{5}$ Department of Emergency Medicine, Korea University Ansan Hospital, Ansan, Republic of Korea; ${ }^{6}$ Division of Pulmonology, Department of Internal Medicine, Keimyung University Dongsan Hospital, Keimyung University School of Medicine, Daegu, Republic of Korea; ${ }^{7}$ Department of Population Health, New York University Grossman School of Medicine, New York, NY, USA; ${ }^{8}$ Institute for Disease Modeling, Seattle, WA, USA

Correspondence: In-Hwan Oh Department of Preventive Medicine, School of Medicine, Kyung Hee University, Seoul, Republic of Korea Fax +82-2-969-0792

Email ihoh@khu.ac.kr
Objective: To identify risk factors for intensive care unit (ICU) admission and mechanical ventilator usage among confirmed coronavirus disease (COVID-19) patients and estimate the effects of mitigation efforts on ICU capacity in Korea.

Patients and Methods: Data on profiles and medical history of all confirmed COVID-19 patients in the past 1 year were extracted from the Korean National Health Insurance System's claims database to assess risk factors for ICU admission and ventilator use. We used a time-series epidemic model to estimate the ICU census in Daegu from the reported hospital data.

Findings: Multivariate regression analysis revealed male sex, old age, and residing in Daegu city as significant risk factors for ICU admission. The number of patients requiring ICU admission exceeded the bed capacity across all Daegu hospitals before March 9, 2020, and therefore, critically ill patients were transferred to nearby hospitals outside Daegu. This finding was consistent with our prediction that the ICU census in Daegu would peak on March 16, 2020, at 160 through mitigation efforts, without which it would have reached 300 by late March 2020 .

Conclusion: Older age and male sex were risk factors for ICU admission. In addition, the geographic location of the hospital seems to contribute to the severity of the COVID-19 patients admitted to the ICU and to the ICU capacity.

Keywords: COVID-19 pandemic, ICU admission, Korea, risk factors

\section{Introduction}

The coronavirus disease (COVID-19) pandemic poses a serious threat to global health and has caused 196,295 deaths globally as of April 27, 2020. ${ }^{1}$ Its case fatality rate (CFR) is estimated to be $0.08 \%-15.49 \%,{ }^{2}$ varying widely across regions, age groups, and presence of comorbidities. Many infected patients have no or mild symptoms, while only approximately $14 \%$ of the symptomatic patients have severe infections requiring hospitalization, and $6 \%$ become critically ill. Therefore, with the rapid spread of the pandemic, the health care system capacity and public health strategies critically impact clinical progression and outcomes. ${ }^{3}$

The overwhelming surge of critically ill COVID-19 patients demands an urgent need for intensive care in terms of space, supplies, doctors, nurses, and paramedical workers. Management of critically ill COVID-19 patients also increases the workload for health 
care workers. Currently, COVID-19 treatment is limited to supportive care without specific medical treatment, and hence, implementation of strict infection control is essential. ${ }^{4}$ Therefore, it is critical for countries with an impending surge of COVID-19 to prepare their health care systems, including intensive care unit (ICU) beds, to provide adequate care to critically ill patients.

In South Korea (S. Korea), the total number of confirmed COVID-19 cases was 10,761 as on April 29, 2020, of which $6852(63.7 \%)$ cases occurred in Daegu city and 1365 (12.68\%) in Gyeongsangbuk province near Daegu city. The number of COVID-19 deaths among the confirmed cases was 248, yielding a nationwide CFR of $2.29 \%{ }^{5}$ The surge in COVID-19 cases was particularly rapid in the second and third weeks of February 2020 in Daegu city and Gyeongsangbuk province, ${ }^{6}$ the majority of which were epidemiologically connected to either the largest clustered transmission in the Shincheonji religious cult group or hospital and community transmission. As a result, the COVID-19 epidemic peaked on February 29, 2020, in Daegu city and on March 6, 2020, in Gyeongsangbuk province, with 656 and 123 new confirmed cases per day, respectively. ${ }^{7}$ The first two fatal cases occurred among self-isolated patients in Daegu while waiting for hospital admission on February 27, 2020, indicating a shortage of hospital capacity in Daegu at that time. ${ }^{8}$

The Korean government quickly implemented containment strategies such as contact tracing, including a full investigation of potentially high-risk groups in congregating facilities. These strategies depended on capable diagnostics $^{9,10}$ and mitigation measures such as social distancing. ${ }^{11}$ In late February 2020, the government introduced a triage system for COVID-19 patients to reduce the burden on the health care system and to prioritize ICU beds for patients with signs of clinical deterioration demanding urgent mechanical ventilation, based on the severity of disease presentation (grades 1 to 4$){ }^{12,13}$ The government also recommended discharge and relocation of patients who were already hospitalized for mild symptoms, to re-allocate the hospital and ICU beds to critically ill patients in Daegu city. However, it is unclear whether the ICU bed capacity was enough to provide sufficient care, or whether the beds had been successfully allocated to all critically ill patients, using the triage or referral system alongside simultaneously ongoing containment and mitigation strategies in S. Korea. Additionally, given the unpredictable nature of respiratory failure, the use of mechanical ventilators as a supportive intervention can have implications in determining timely ICU capacity. ${ }^{4}$

The primary objective of this study was to identify risk factors for ICU admission and mechanical ventilator use among confirmed COVID-19 patients in S. Korea. The secondary objective was to investigate the timeliness and relevance of ICU allocation among confirmed COVID-19 patients in Daegu and S. Korea overall using the national insurance claims data and the epidemic prediction model.

\section{Patients and Methods}

\section{National Health Insurance System}

We used the database of the Health Insurance Review \& Assessment Service (HIRA, Seoul, South Korea), a government-affiliated agency that assesses the accuracy of claims made in the National Health Insurance System (NHIS), ${ }^{14}$ a mandatory health insurance system covering $96.6 \%$ of the entire S. Korean population of 48.6 million, and National Medical Aid, which covers 3.5\% of the population. ${ }^{14}$ The HIRA database includes diagnostic codes (International Classification of Diseases, 10 Revision [ICD-10]), prescribed medications, and all medical services provided, and it has been widely used in many studies. ${ }^{15}$

All medical service costs for COVID-19 tests and treatments are covered by the NHIS, including negative tests. Therefore, the HIRA data cover virtually every case tested for COVID-19 in S. Korea, regardless of the test outcome. Currently, HIRA allows public use of their open claims data on COVID-19 tests and treatments and supports studies that use its data. ${ }^{16}$

\section{Study Population and Variables}

This study included patients confirmed with COVID-19 who used any related medical services until March 8, 2020, approximately 9 days after the peak of COVID19 cases in Daegu. Data on all COVID-19-related medical services, medical history for the past 1 year, and costs were extracted from the HIRA database (Figure 1). We examined the sociodemographic and clinical characteristics of patients including comorbidities as potential risk factors for ICU admission and ventilator use. The sociodemographic characteristics included age, sex, and location of the medical facility. The comorbidities included hypertension, diabetes mellitus (DM), cancer, chronic obstructive pulmonary disease (COPD), and ischemic heart disease. Patients with confirmed 
COVID-19 who used medical facilities due to any of the above conditions (based on ICD-10 codes) within 1 year of the diagnosis were regarded as having these comorbidities. ICD-10 codes were used to identify cases such as cancer (all C codes), ischemic heart disease (I20-I25), COPD (J40, J41, J43, J44, J47), hypertension (I10, I11, I12, I13, I15), and DM (E10-E14). Only cases identified under the main ICD codes were included. We extracted data on the usage of medical diagnostics such as computed tomography (CT), and medication with hydroxychloroquine and lopinavir/ritonavir $\left(\right.$ Kaletra $\left.^{\circledR}\right)$. We also analyzed the duration of hospital stay and associated medical costs incurred to the health care system (USD to KRW exchange rate: $1221 \mathrm{KRW}$ per $1 \mathrm{US}$ dollar).

\section{Statistical Analysis}

Chi-square and $t$-tests were used to detect univariate associations for categorical and continuous variables, respectively. Multivariate logistic regression analysis was used to determine risk factors such as sex, age, beneficiary state, location of medical facility, and comorbidities. For each risk factor, an adjusted odds ratio [aOR] and its 95\% confidence interval $[95 \% \mathrm{CI}]$ were reported. $\mathrm{P}<0.05$ was considered to indicate statistical significance. Statistical analyses were performed using SAS Enterprise Guide 7.1 (Cary, NC, USA).

\section{Epidemic Model to Predict ICU Census}

We determined the ICU census (i.e., the number of patients in the ICU due to COVID-19) in Daegu based on the projected epidemic growth curve using a time-series stochastic SEIR transmission model. ${ }^{17}$ Details of the epidemic and health care system utilization in S. Korea are presented in these studies. ${ }^{5,18,19}$ Using the epidemiological and clinical data in Daegu, ${ }^{5,18,19}$ we assumed that $69.1 \%$ of infected patients were asymptomatic or presented with very mild symptoms, $22.4 \%$ with mild symptoms, $6.4 \%$ with severe symptoms, and 3.0\% with critical illness. Approximately $8.6 \%$ of all hospitalized patients were assumed to be admitted to the ICU. According to government policies, nearly all confirmed cases were isolated and admitted to either a monitoring facility (for asymptomatic or very mildly symptomatic cases) or a hospital (for patients with mild-tocritical symptoms). Time to symptom onset and time from symptom onset to first admission at the hospital were assumed to be 5.1 days and 5 days, respectively. ${ }^{20}$ Critically ill patients were assumed to have stayed in the ICU for either 20 days (survivors) or 3 days (non-survivors).
Data on disease progression and ICU census were obtained using the Korean Centers for Disease Control and Prevention and local Daegu city surveillance data. ${ }^{5,18}$ Based on the policy and interventions implemented in Daegu, we calibrated our model and assumed an initial reproduction number $\left(\mathrm{R}_{0}\right)$ of 3.2 and that the effective reproduction number was reduced by $10 \%$ by February 22 , $50 \%$ by February 27, and $90 \%$ by March 5, 2020, through a combination of different mitigation efforts such as social distancing, contact tracing, early quarantine of all nonsymptomatic and symptomatic cases, wide testing, and close monitoring. ${ }^{9,21}$

\section{Ethical Statement}

This study was approved by the Kyung Hee University Institute Research Board (KHSIRB-20-164). Informed consent was not required because this study used deidentified, open (publicly available) data.

\section{Results}

\section{Reported and Predicted ICU Census in Daegu and S. Korea}

The ICU admission rates in Daegu, Gyeongsangbuk province, and other regions were $3.2 \%$ (34/1077), 2.3\% (4/171), and $1.2 \%(42 / 3494)$, respectively, based on the national health insurance claims data. The reported ICU census exceeded the available ICU bed capacity (by approximately 60) across all hospitals in Daegu before March 9, remained at maximum capacity until April 6, and then gradually declined (Figure 2). Therefore, additional 50-60 critically ill patients were transferred to hospitals outside Daegu. In the epidemic prediction model, we estimated that the peak time of ICU census in Daegu would have been March 16 ( $\sim 60$ ICU census), approximately 2 weeks after the peak of new daily confirmed cases, followed by a gradual decline until the end of April. Assuming a 70\% reduction after March 5, the ICU census would have continuously increased and reached 300 by the second week of April. While assuming 50\% reduction, the ICU census would have reached 300 by March 25 and 1000 by April 13, respectively.

\section{Risk Factors for ICU Admission}

A total of 4742 patients who had a confirmed diagnosis of COVID-19 were included in the analysis. The number of males and females was 2156 and 2586, respectively. Mean patient age was $41.8 \pm 19.0$ years (Table 1). A total of 80 of 4742 patients $(1.7 \%)$ were admitted to the ICU. The 


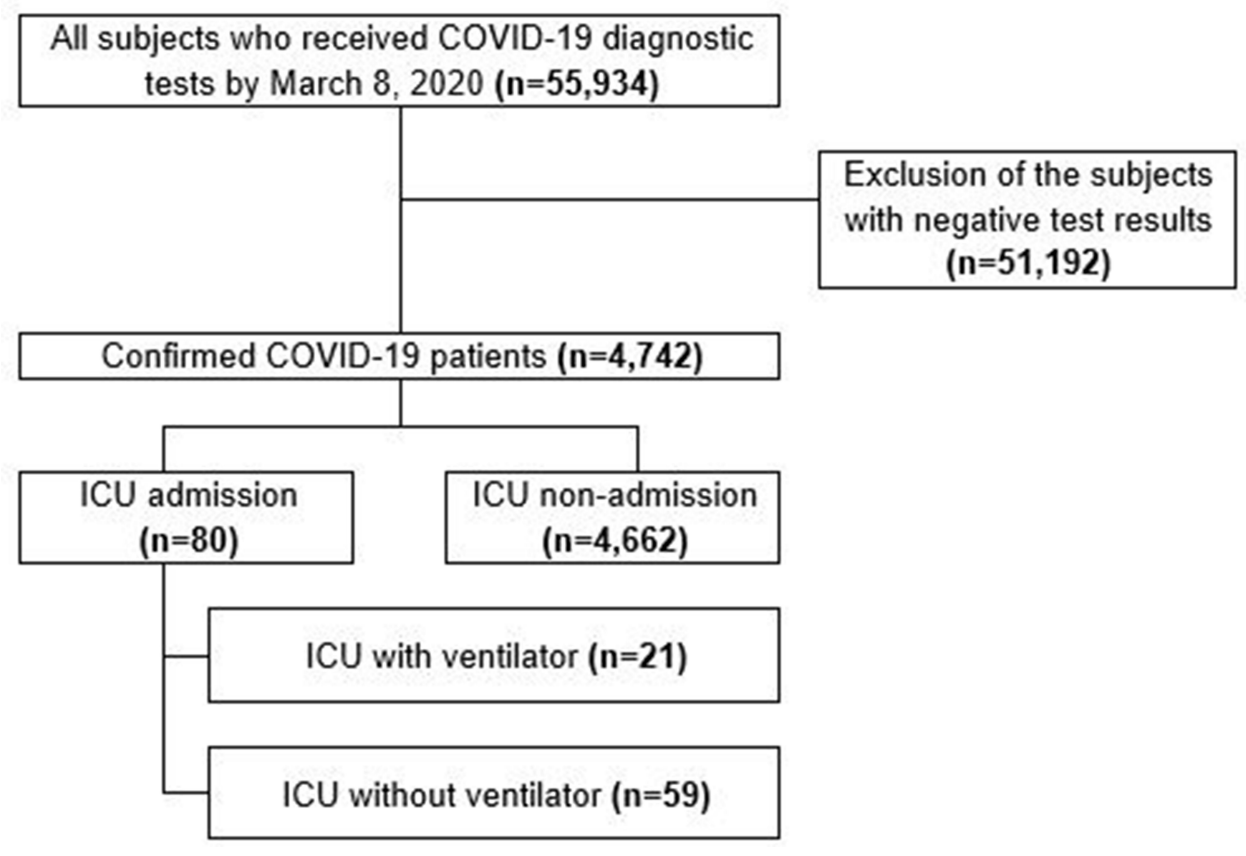

Figure I Flow diagram of the subjects included in this study. We selected 4,742 confirmed COVID-19 patients in 55,934 subjects who received COVID-19 diagnostic tests by March 8, 2020, except for the subjects with negative test results.

Abbreviations: NHIS, National Health Insurance System; ICU, Intensive Care Unit.

number of patients with malignancy, COPD, ischemic heart disease, hypertension, and diabetes mellitus was $284(6.0 \%), 400$ (8.4\%), 197 (4.2\%), 506 (10.7\%), and $351(7.4 \%)$, respectively. The rates of ICU admission among patients with each of these comorbidities were 4.6\% (13/284), 1.8\% (7/400), 3.6\% (7/197), 3.8\% (19/ 506), and 4.0\% (14/351), respectively (Table 1). Male sex, old age, hospital, region, hospital transfer, comorbidities (malignancy, ischemic heart disease, hypertension, and diabetes), and $\mathrm{SpO}_{2}$ levels were found to be significant risk factors for ICU admission $(\mathrm{P}<0.05)$ in the univariate analysis. The lenght of hospital admission was significantly longer among patients admitted to the ICU (19.5 \pm 11.6 days) than that of those who were not admitted to the ICU $(4.9 \pm 7.5$ days $)(\mathrm{P}<0.001)$. The incurred costs assessed using national insurance data were also significantly higher for patients admitted to the ICU $(\$ 10,126.76$ $\pm 5,979.72 \quad$ vs. US $\$ 986.26 \pm 2,206.41) \quad(\mathrm{P}<0.001)$. Multivariate logistic regression analysis revealed that male sex $(\mathrm{aOR}=2.075 ; 95 \%$ CI [1.300,3.300] $)$, old age $(\mathrm{aOR}=1.039 ; 95 \%$ CI $[1.025,1.053])$, and Daegu city $(\mathrm{aOR}=2.123 ; 95 \%$ CI $[1.317,3.413])$ were significant risk factors for ICU admission (Table 2). Malignancy, ischemic heart disease, hypertension, and diabetes were significant risk factors for ICU admission in univariate analysis, but the associations were no longer significant after adjusting for other variables (Table 2).

\section{Mechanical Ventilation in the ICU}

Among 80 patients admitted to the ICU, 21 (26.3\%) were treated with mechanical ventilation (Table 3). The mean age of patients was significantly higher for those who received mechanical ventilation $(67.8 \pm 10.0$ years $)$ than for those who did not $(54.9 \pm 16.6$ years $)$. Mechanical ventilation was performed more frequently in Daegu (17/ $34,50 \%)$ than in other regions $(2 / 42,4.8 \%)(\mathrm{P}<0.001)$. Of the 21 patients who received mechanical ventilation, chest CT scans had not been taken for 19 patients $(90.5 \%)$ $(\mathrm{P}<0.001)$. Hydroxychloroquine was prescribed to a higher proportion of patients who received mechanical ventilation $(41.7 \%)$ than those who did not $(13 \%)$ $(\mathrm{P}=0.005)$. Multivariate logistic regression analysis revealed old age $(\mathrm{aOR}=1.067 ; 95 \%$ CI $[1.008,1.130])$ and Daegu city $(\mathrm{aOR}=29.412 ; 95 \% \mathrm{CI}[4.695,200])$ to be significant risk factors for mechanical ventilation in the ICU (Table 4), whereas comorbidities and hospital transfer did not show any significant association with mechanical ventilation in the ICU in both univariate and multivariate 


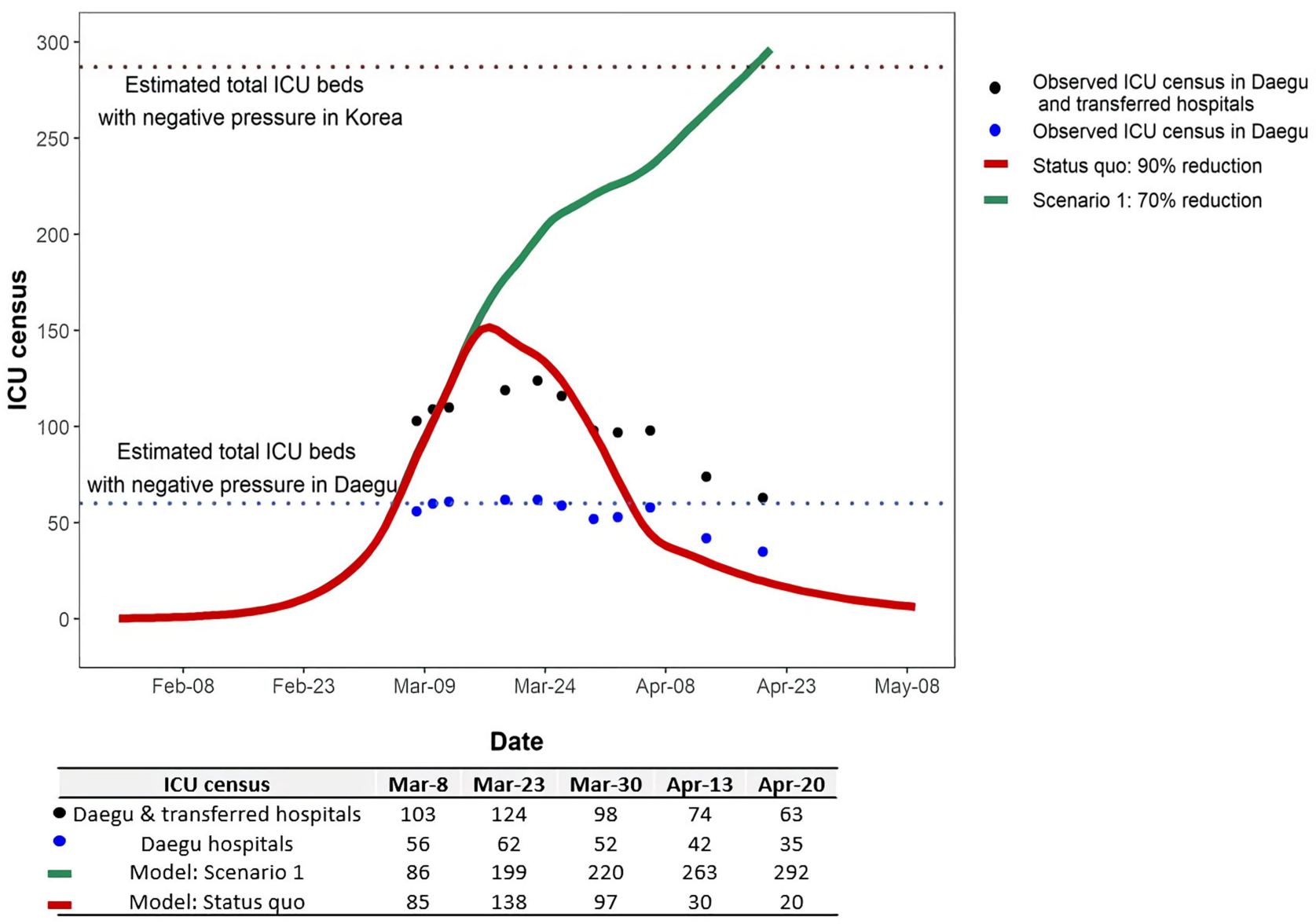

Figure 2 ICU census among the confirmed COVID-19 cases in Daegu. Blue large dots represent the observed ICU census in Daegu hospitals, while large black dots represent the estimated total number of patients including those who were critically ill and transferred to the hospitals in other regions once the hospitals in Daegu reached the critical point for ICU capacity. The model estimates about 70\% (Scenariol, green line) and $90 \%$ ("Status quo", red line) reduction in the effective reproduction number by February 27th and March 5th, respectively. Horizontal lower line (small blue-botted line) and upper line (small black-dotted line) represent estimated total ICU beds in Daegu (67 beds) and South Korea (around 290 beds) ${ }^{18}$, respectively.

logistic regression analyses. Interestingly, 8 of 29 patients $(27.6 \%)$ were treated with mechanical ventilation in a general ward setting in a negative-pressure room.

\section{Discussion}

Age had a significant effect on ICU admission and usage of mechanical ventilation in the ICU among confirmed COVID-19 patients. In addition, less intensive care without mechanical ventilation for COVID-19 patients seems to have been performed outside of Daegu, irrespective of the underlying comorbidities. Overall, the drastic reduction in contact rates through containment strategies critically contributed to the management of the ICU census during the early COVID-19 epidemic in S. Korea.

In this study, we attempted to identify potential risk factors for ICU admission and ventilator usage, both of which are considered proxy indicators of the severity of the disease. Similar associations with age and male sex have been reported elsewhere. ${ }^{22}$ We found that the effect of comorbidities was not significant on the severity of COVID-19 disease. One plausible explanation is that a much higher proportion of younger patients without comorbidities were infected with COVID-19 in S. Korea. ${ }^{23}$ An analysis of our large sample covering 164 institutions revealed that the effect of comorbidities previously known to be risk factors was no longer significant upon adjustment for age and sex. Therefore, the effect of comorbidities on COVID-19 severity needs to be further investigated. Particularly, further analyses of mortality should be conducted based on individualized clinical data after excluding life-sustaining treatment that was stopped due to old age.

Our prediction model estimated that the peak of the ICU census had occurred around March 19, 2020. By this time, which was approximately 2 weeks after the number of confirmed cases peaked on February 29 in Daegu, the 
Table I Rates of ICU Admission Among Confirmed COVID-19 Patients

\begin{tabular}{|c|c|c|c|c|c|}
\hline \multirow{2}{*}{\multicolumn{2}{|c|}{ Patient Characteristics }} & Total & ICU Admission & ICU Non-Admission & \multirow[t]{2}{*}{ p-value } \\
\hline & & No. (\%) of Patients & No. (\%) ${ }^{a}$ of Patients & No. (\%) of Patients & \\
\hline \multicolumn{2}{|c|}{$\begin{array}{l}\text { Total } \\
\text { Age, Years (mean } \pm S D) \\
\text { Cost, US Dollar (mean } \pm S D \text { ) } \\
\text { Duration of hospital stays, days (mean } \pm S D \text { ) }\end{array}$} & $\begin{array}{l}4742(100) \\
4 I .8 \pm 19.0 \\
|| 3.67 \pm 2,60|.4| \\
5.2 \pm 7.9\end{array}$ & $\begin{array}{l}80(100) \\
58.3 \pm 16.1 \\
10,126.76 \pm 5,979.72 \\
19.5 \pm 11.6\end{array}$ & $\begin{array}{l}4662(100) \\
41.5 \pm 18.9 \\
986.26 \pm 2,206.41 \\
4.9 \pm 7.5\end{array}$ & $\begin{array}{l}<0.001^{c} \\
<0.001^{c} \\
<0.001^{c}\end{array}$ \\
\hline Sex & $\begin{array}{l}\text { Male } \\
\text { Female }\end{array}$ & $\begin{array}{l}2156(45.5) \\
2586(54.5)\end{array}$ & $\begin{array}{l}50(62.5) \\
30(37.5)\end{array}$ & $\begin{array}{l}2106(45.2) \\
2556(54.8)\end{array}$ & 0.002 \\
\hline Type of insurance & $\begin{array}{l}\text { Health insurance } \\
\text { Medical aid }\end{array}$ & $\begin{array}{l}4507(95.0) \\
235(5.0)\end{array}$ & $\begin{array}{l}73(91.3) \\
7(8.8)\end{array}$ & $\begin{array}{l}4434(95.1) \\
228(4.9)\end{array}$ & $0.116^{b}$ \\
\hline Location of facility & $\begin{array}{l}\text { Daegu city } \\
\text { Gyeongsang buk province } \\
\text { Other }\end{array}$ & $\begin{array}{l}1077(22.7) \\
171(3.6) \\
3494(73.7)\end{array}$ & $\begin{array}{l}34(42.5) \\
4(5.0) \\
42(52.5)\end{array}$ & $\begin{array}{l}1043(22.4) \\
167(3.6) \\
3452(74.0)\end{array}$ & $<0.001$ \\
\hline Hospital transfer & $\begin{array}{l}\text { Yes } \\
\text { No }\end{array}$ & $\begin{array}{l}57(1.2) \\
4685(98.8)\end{array}$ & $\begin{array}{l}7(8.8) \\
73(91.3)\end{array}$ & $\begin{array}{l}50(1.1) \\
4612(98.9)\end{array}$ & $<0.001$ \\
\hline Malignancy & $\begin{array}{l}\text { Yes } \\
\text { No }\end{array}$ & $\begin{array}{l}284(6.0) \\
4458(94.0)\end{array}$ & $\begin{array}{l}13(16.3) \\
67(83.8)\end{array}$ & $\begin{array}{l}27 I(5.8) \\
439 I(94.2)\end{array}$ & $0.008^{b}$ \\
\hline COPD & $\begin{array}{l}\text { Yes } \\
\text { No }\end{array}$ & $\begin{array}{l}400(8.4) \\
4342(91.6)\end{array}$ & $\begin{array}{l}7(8.8) \\
73(91.3)\end{array}$ & $\begin{array}{l}393(8.4) \\
4269(91.6)\end{array}$ & 0.919 \\
\hline Ischemic heart disease & $\begin{array}{l}\text { Yes } \\
\text { No }\end{array}$ & $\begin{array}{l}197(4.2) \\
4545(95.8)\end{array}$ & $\begin{array}{l}7(8.8) \\
73(91.3)\end{array}$ & $\begin{array}{l}190(4.1) \\
4472(95.9)\end{array}$ & $0.047^{b}$ \\
\hline Hypertension & $\begin{array}{l}\text { Yes } \\
\text { No }\end{array}$ & $\begin{array}{l}506(10.7) \\
4236(89.3)\end{array}$ & $\begin{array}{l}19(23.8) \\
61(76.3)\end{array}$ & $\begin{array}{l}487(10.4) \\
4175(89.6)\end{array}$ & 0.001 \\
\hline Diabetes mellitus & $\begin{array}{l}\text { Yes } \\
\text { No }\end{array}$ & $\begin{array}{l}351(7.4) \\
4391(92.6)\end{array}$ & $\begin{array}{l}14(17.5) \\
66(82.5)\end{array}$ & $\begin{array}{l}337(7.2) \\
4325(92.8)\end{array}$ & 0.005 \\
\hline Mechanical ventilation & $\begin{array}{l}\text { Yes } \\
\text { No }\end{array}$ & $\begin{array}{l}29(0.6) \\
4713(99.4)\end{array}$ & $\begin{array}{l}21(26.3) \\
59(73.8)\end{array}$ & $\begin{array}{l}8(0.2) \\
4654(99.8)\end{array}$ & $<0.00 \mathrm{I}^{\mathrm{b}}$ \\
\hline $\begin{array}{l}\text { Chest } \\
\text { CT scan }\end{array}$ & $\begin{array}{l}\text { Yes } \\
\text { No }\end{array}$ & $\begin{array}{l}465(9.8) \\
4277(90.1)\end{array}$ & $\begin{array}{l}38(47.5) \\
42(52.5)\end{array}$ & $\begin{array}{l}427(9.2) \\
4235(90.8)\end{array}$ & $<0.001$ \\
\hline Oxygen saturation ( $\mathrm{SpO} 2)$ & $\begin{array}{l}\text { Yes } \\
\text { No }\end{array}$ & $\begin{array}{l}978(20.6) \\
3764(79.4)\end{array}$ & $\begin{array}{l}66(82.5) \\
14(17.5)\end{array}$ & $\begin{array}{l}912(19.6) \\
3750(80.4)\end{array}$ & $<0.001$ \\
\hline
\end{tabular}

Notes: ${ }^{a}$ Shows row percentage. ${ }^{b}$ Fisher's exact test; ${ }^{c}$-test.

Abbreviations: COPD, chronic obstructive pulmonary disease; CT, computed tomography.

ICU capacity (approximately 60 beds) had already reached its limit. Even though S. Korea ranks second in the number of general hospital beds per population among the 35 Organization for Economic Co-operation and Development (OECD) countries, ${ }^{24}$ the rapid surge after a massive outbreak in a religious cult group (Shinchonji) quickly overwhelmed the health system and ICU capacity in Daegu.

The aggressive containment strategies, including early detection through massive testing and diagnosis, and isolation of both asymptomatic and symptomatic cases from the early period of the epidemic, ${ }^{25}$ drastically prevented further community transmission. We estimated that without these containment effortsand relocation of the patients based on clinical severity, the ICU capacity could have been already overwhelmed by early March.

The rates of ICU admission among confirmed COVID-19 cases and usage of mechanical ventilation among those admitted to ICU were low as $1.7 \%$ and $26.3 \%$, respectively, compared with $5.0-12 \%{ }^{26,27}$ and $45-64 \%$, respectively, ${ }^{27,28}$ reported in other countries ${ }^{27,28}$ because confirmed patients with mild or no symptoms who would have been self- 
Table 2 Logistic Regression Analysis of Characteristics Among Patients Admitted to the ICU for COVID-19

\begin{tabular}{|c|c|c|c|c|c|}
\hline \multicolumn{2}{|c|}{ Patient Characteristics $(\mathrm{N}=4742)$} & \multicolumn{2}{|l|}{ Crude OR } & \multicolumn{2}{|c|}{ Adjusted $O{ }^{b}$} \\
\hline & & \multirow{2}{*}{$\begin{array}{l}\text { Estimate } \\
\mathrm{I} .045\end{array}$} & \multirow{2}{*}{$\begin{array}{l}95 \% \mathrm{Cl} \\
1.033,1.057^{\mathrm{a}}\end{array}$} & \multirow{2}{*}{$\begin{array}{l}\text { Estimate } \\
1.039\end{array}$} & \multirow{2}{*}{$\begin{array}{l}95 \% \mathrm{Cl} \\
1.025,1.053^{\mathrm{a}}\end{array}$} \\
\hline Age & & & & & \\
\hline Sex & $\begin{array}{l}\text { Female } \\
\text { Male }\end{array}$ & $\begin{array}{l}\text { Ref } \\
2.024\end{array}$ & $\begin{array}{l}\text { Ref } \\
\text { I.282, 3.195 }\end{array}$ & $\begin{array}{l}\text { Ref } \\
2.075\end{array}$ & $\begin{array}{l}\text { Ref } \\
1.300,3.300^{a}\end{array}$ \\
\hline Type of insurance & $\begin{array}{l}\text { Health insurance } \\
\text { Medical aid }\end{array}$ & $\begin{array}{l}\text { Ref } \\
1.865\end{array}$ & $\begin{array}{l}\text { Ref } \\
0.849,4.096\end{array}$ & $\begin{array}{l}\text { Ref } \\
1.06 \mathrm{I}\end{array}$ & $\begin{array}{l}\text { Ref } \\
0.47 \mathrm{I}, 2.390\end{array}$ \\
\hline Location of facility & $\begin{array}{l}\text { Other } \\
\text { Daegu } \\
\text { Gyeongsangbuk province }\end{array}$ & $\begin{array}{l}\text { Ref } \\
2.680 \\
1.969\end{array}$ & $\begin{array}{l}\text { Ref } \\
\text { I.696, } 4.234 \\
0.698,5.555\end{array}$ & $\begin{array}{l}\text { Ref } \\
2.123 \\
2.134\end{array}$ & $\begin{array}{l}\text { Ref } \\
1.317,3.413^{a} \\
1.181,3.018\end{array}$ \\
\hline Malignancy & $\begin{array}{l}\text { No } \\
\text { Yes }\end{array}$ & $\begin{array}{l}\text { Ref } \\
3.145\end{array}$ & $\begin{array}{l}\text { Ref } \\
\text { I.7I5, } 5.780\end{array}$ & $\begin{array}{l}\text { Ref } \\
1.464\end{array}$ & $\begin{array}{l}\text { Ref } \\
0.769,2.786\end{array}$ \\
\hline COPD & $\begin{array}{l}\text { No } \\
\text { Yes }\end{array}$ & $\begin{array}{l}\text { Ref } \\
1.043\end{array}$ & $\begin{array}{l}\text { Ref } \\
0.477,2.278\end{array}$ & $\begin{array}{l}\text { Ref } \\
0.741\end{array}$ & $\begin{array}{l}\text { Ref } \\
0.332, \quad 1.653\end{array}$ \\
\hline Ischemic heart disease & $\begin{array}{l}\text { No } \\
\text { Yes }\end{array}$ & $\begin{array}{l}\text { Ref } \\
2.257\end{array}$ & $\begin{array}{l}\text { Ref } \\
1.026,4.975\end{array}$ & $\begin{array}{l}\text { Ref } \\
0.881\end{array}$ & $\begin{array}{l}\text { Ref } \\
0.385,2.016\end{array}$ \\
\hline Hypertension & $\begin{array}{l}\text { No } \\
\text { Yes }\end{array}$ & $\begin{array}{l}\text { Ref } \\
2.674\end{array}$ & $\begin{array}{l}\text { Ref } \\
\text { I.582, } 4.505\end{array}$ & $\begin{array}{l}\text { Ref } \\
1.353\end{array}$ & $\begin{array}{l}\text { Ref } \\
0.77 I, 2.38 I\end{array}$ \\
\hline Diabetes mellitus & $\begin{array}{l}\text { No } \\
\text { Yes }\end{array}$ & $\begin{array}{l}\text { Ref } \\
2.725\end{array}$ & $\begin{array}{l}\text { Ref } \\
1.513,4.902\end{array}$ & $\begin{array}{l}\text { Ref } \\
1.079\end{array}$ & $\begin{array}{l}\text { Ref } \\
0.576,2.020\end{array}$ \\
\hline
\end{tabular}

Notes: ${ }^{\mathrm{a}} \mathrm{p}$-value $<0.05 .{ }^{\mathrm{b}} \mathrm{Adjusted}$ for all other variables shown in the column.

Abbreviations: $\mathrm{OR}$, odds ratio; $\mathrm{Cl}$, confidence interval; COPD, chronic obstructive pulmonary disease.

isolated at home in other countries were all admitted to hospital wards or monitoring facilities in response to the government's containment strategies ${ }^{21}$ in S. Korea. The World Health Organization has recommended an objective scoring system to measure disease severity using a respiratory rate of $>30$ breaths/min, severe respiratory distress, or $\mathrm{SpO}_{2}<90 \%$. However, during the post-admission stage, transfer from the hospital general wards to ICU could not be easily decided based on the objective severity score system such as a modified early warning score (MEWS) as the clinical course of the patients could deteriorate unexpectedly. ${ }^{12,13}$ Therefore, to avoid exceeding the ICU capacity in Daegu, ICU beds were re-allocated and prioritized admission of most critically ill patients, and less critical patients were transferred to hospitals outside Daegu. However, in case of aseveral nationwide epidemic, central coordination of ICU arrangement should be considered to monitor ICU capacity in all hospitals in S. Korea.

Given that the number of patients in the ICU requiring ventilators for treatment was significantly higher in Daegu $(50 \%)$ and Gyeongsang province $(50 \%)$ than in other regions (4.8\%), fewer critically ill patients were admitted to the ICU to monitor disease progression in the other regions during the early stage of the epidemic. Previous national ICU adequacy evaluation reports indicated that quality measures of ICU in Daegu \& Gyeongsang province ranked second among the six districts in providing healthcare for more severe patients (Supplement 1). Therefore, prompt early communication and timely referral of patients to less burdened regions should be considered in a rapid surge, in addition to increasing ICU capacity. ${ }^{18}$ However, it is also possible that patients in the other regions were closely monitored with $\mathrm{O}_{2}$ treatment in the ICU beforehand to prepare the impending intubation for ventilator care, as the critical interventional procedure can be time- and labor-intensive on infection prevention circumstances. ${ }^{26}$

This study has some limitations. First, because the results are based on the HIRA hospital claims data up to March 8, 2020, some of the hospital activities could have not been claimed until that time. However, our data cover approximately $50 \%(4327 / 10,722)$ of the confirmed cases as of April 28, 2020, which can be representative of the national sample during the early epidemic. Second, if claims are being delayed under the current epidemic, our 
Table 3 Rates of Ventilator Use Among ICU-Admitted COVID-19 Patients

\begin{tabular}{|c|c|c|c|c|c|}
\hline \multicolumn{2}{|c|}{ Patient Characteristics } & \multirow{2}{*}{$\begin{array}{l}\text { Total } \\
\text { No. (\%) }\end{array}$} & \multirow{2}{*}{$\begin{array}{l}\text { ICU with } \\
\text { Ventilator } \\
\text { No. (\%) }\end{array}$} & \multirow{2}{*}{$\begin{array}{l}\text { ICU without } \\
\text { Ventilator } \\
\text { No. (\%) }{ }^{a}\end{array}$} & \multirow[t]{2}{*}{ p-value } \\
\hline & & & & & \\
\hline \multirow{4}{*}{\multicolumn{2}{|c|}{$\begin{array}{l}\text { Total } \\
\text { Age, Years (mean } \pm S D) \\
\text { Cost, US Dollar (mean } \pm S D) \\
\text { Duration, days (mean } \pm S D \text { ) }\end{array}$}} & $80(100)$ & $21(100)$ & $59(100)$ & \\
\hline & & $58.3 \pm 16.1$ & $67.8 \pm 10.0$ & $54.9 \pm 16.6$ & $0.001^{c}$ \\
\hline & & $|0| 28.4 \mid \pm 5,980.70$, & $|3,257.8| \pm 7,698.9 \mid$ & $9,012.18 \pm 4,842.59$ & $0.005^{c}$ \\
\hline & & $19.5 \pm 11.6$ & $14.3 \pm 8.6$ & $21.3 \pm 12.0$ & $0.006^{c}$ \\
\hline \multirow[t]{2}{*}{ Sex } & Male & $50(62.5)$ & I5 (7I.4) & $35(59.3)$ & 0.325 \\
\hline & Female & $30(37.5)$ & $6(28.6)$ & $24(40.7)$ & \\
\hline \multirow[t]{2}{*}{ Insurance } & Health insurance & $73(91.3)$ & $20(95.2)$ & $53(89.8)$ & $0.669^{b}$ \\
\hline & Medical aid & $7(8.8)$ & I (4.8) & $6(10.2)$ & \\
\hline \multirow[t]{4}{*}{ Location of facility } & Daegu & $34(42.5)$ & $17(8 \mid .0)$ & $17(28.8)$ & $<0.001$ \\
\hline & Gyeongsangbuk & $4(5.0)$ & $2(9.5)$ & $2(3.4)$ & \\
\hline & province & & & & \\
\hline & Other & $42(52.5)$ & $2(9.5)$ & $40(67.8)$ & \\
\hline \multirow[t]{2}{*}{ Hospital transfer } & Yes & $73(91.3)$ & $17(81.0)$ & $56(94.9)$ & $0.073^{b}$ \\
\hline & No & $7(8.8)$ & $4(19.0)$ & $3(5.1)$ & \\
\hline \multirow[t]{2}{*}{ Malignancy } & Yes & I3 (16.3) & $4(19.0)$ & $9(15.3)$ & $0.735^{b}$ \\
\hline & No & $67(83.8)$ & I7 (8I.0) & $50(84.7)$ & \\
\hline \multirow[t]{2}{*}{ COPD } & Yes & $7(8.8)$ & I (4.8) & $6(10.2)$ & $0.669^{b}$ \\
\hline & No & $73(91.3)$ & $20(95.2)$ & $53(89.8)$ & \\
\hline \multirow[t]{2}{*}{ Ischemic heart disease } & Yes & $7(8.8)$ & $4(19.0)$ & $3(5.1)$ & $0.073^{b}$ \\
\hline & No & 73 (9l.3) & $17(8 \mid .0)$ & $56(94.9)$ & \\
\hline \multirow[t]{2}{*}{ Hypertension } & Yes & $19(23.8)$ & $6(28.6)$ & $13(22.0)$ & $0.561^{b}$ \\
\hline & No & $61(76.3)$ & I5 (7I.4) & $46(78.0)$ & \\
\hline \multirow[t]{2}{*}{ Diabetes mellitus } & Yes & $14(17.5)$ & $5(23.8)$ & $9(15.3)$ & $0.504^{b}$ \\
\hline & No & 66 (82.5) & $16(76.2)$ & $50(84.7)$ & \\
\hline \multirow[t]{2}{*}{ Chest CT scan } & Yes & $38(47.5)$ & $2(9.5)$ & $36(61.0)$ & $<0.001$ \\
\hline & No & $42(52.5)$ & $19(90.5)$ & $23(39.0)$ & \\
\hline \multirow{2}{*}{$\begin{array}{l}\text { Oxygen saturation } \\
(\mathrm{SpO} 2)\end{array}$} & Yes & $66(82.5)$ & $21(100.0)$ & $45(76.3)$ & $0.016^{b}$ \\
\hline & No & I4 (I7.5) & $0(0.0)$ & 14 (23.7) & \\
\hline \multirow{2}{*}{$\begin{array}{l}\text { Prescribed interferon } \\
\text { (IFN) }\end{array}$} & Yes & $6(7.5)$ & $4(19.0)$ & $2(3.4)$ & $0.038^{b}$ \\
\hline & No & $74(92.5)$ & $17(81.0)$ & $57(96.6)$ & \\
\hline \multirow[t]{2}{*}{ Prescribed Kaletra ${ }^{\circledR}$} & Yes & $68(85.0)$ & $20(95.1)$ & $48(81.4)$ & $0.168^{b}$ \\
\hline & No & $12(15.0)$ & I (4.8) & II (I8.6) & \\
\hline \multirow[t]{2}{*}{ Prescribed HCQ } & Yes & $36(45.0)$ & I5 (7I.4) & $21(35.6)$ & 0.005 \\
\hline & No & 44 (55.0) & $6(28.6)$ & 38 (64.4) & \\
\hline
\end{tabular}

Notes: ${ }^{a}$ Row percentage. ${ }^{b}$ Fisher's exact test; ${ }^{c}$-test.

Abbreviations: COPD, chronic obstructive pulmonary disease; CT, computed tomography; HCQ, hydroxychloroquine.

analysis could have missed some data on the patients who had been admitted and treated in hospitals before March 8, 2020. Third, the claims data did not include the clinical records of individual patients; therefore, the actual ICU status could have been underestimated. Lastly, some patient data from special COVID-19 monitoring facilities could have been missed because the claims from these facilities were more recently included in the HIRA national claims database. Nevertheless, this study provides valuable information about the effect of comorbidities and 
Table 4 Logistic Regression Analysis of Ventilator Usage Among COVID-19 Patients Admitted to ICU

\begin{tabular}{|c|c|c|c|c|c|}
\hline \multicolumn{2}{|c|}{ Patient Characteristics $(\mathrm{N}=\mathbf{8 0})$} & \multicolumn{2}{|l|}{ Crude OR } & \multicolumn{2}{|c|}{ Adjusted OR } \\
\hline & & Estimate & $95 \% \mathrm{Cl}$ & Estimate & $95 \% \mathrm{Cl}$ \\
\hline Age & & 1.064 & $1.021,1.109^{\mathrm{a}}$ & 1.067 & $1.008,1.130^{\mathrm{a}}$ \\
\hline Sex & $\begin{array}{l}\text { Female } \\
\text { Male }\end{array}$ & $\begin{array}{l}\text { Ref } \\
1.715\end{array}$ & $\begin{array}{l}\text { Ref } \\
0.849,5.051\end{array}$ & $\begin{array}{l}\text { Ref } \\
3.247\end{array}$ & $\begin{array}{l}\text { Ref } \\
0.685,15.385\end{array}$ \\
\hline Insurance & $\begin{array}{l}\text { Health insurance } \\
\text { Medical aid }\end{array}$ & $\begin{array}{l}\text { Ref } \\
0.442\end{array}$ & $\begin{array}{l}\text { Ref } \\
0.050,3.902\end{array}$ & $\begin{array}{l}\text { Ref } \\
0.146\end{array}$ & $\begin{array}{l}\text { Ref } \\
0.010,2.062\end{array}$ \\
\hline Location of facility & $\begin{array}{l}\text { Other } \\
\text { Daegu } \\
\text { Gyeongsangbuk province }\end{array}$ & $\begin{array}{l}\text { Ref } \\
19.995 \\
19.995\end{array}$ & $\begin{array}{l}\text { Ref } \\
4.155,96.209 \\
1.777,224.920\end{array}$ & $\begin{array}{l}\text { Ref } \\
29.412 \\
14.118\end{array}$ & $\begin{array}{l}\text { Ref } \\
4.695,200.000^{a} \\
19.400,105.737\end{array}$ \\
\hline Malignancy & $\begin{array}{l}\text { No } \\
\text { Yes }\end{array}$ & $\begin{array}{l}\text { Ref } \\
\text { I.307 }\end{array}$ & $\begin{array}{l}\text { Ref } \\
0.479,4.808\end{array}$ & $\begin{array}{l}\text { Ref } \\
0.938\end{array}$ & $\begin{array}{l}\text { Ref } \\
0.138,6.410\end{array}$ \\
\hline COPD & $\begin{array}{l}\text { No } \\
\text { Yes }\end{array}$ & $\begin{array}{l}\text { Ref } \\
2.262\end{array}$ & $\begin{array}{l}\text { Ref } \\
0.256,20.000\end{array}$ & $\begin{array}{l}\text { Ref } \\
0.435\end{array}$ & $\begin{array}{l}\text { Ref } \\
0.020,9.615\end{array}$ \\
\hline Ischemic heart disease & $\begin{array}{l}\text { No } \\
\text { Yes }\end{array}$ & $\begin{array}{l}\text { Ref } \\
4.386\end{array}$ & $\begin{array}{l}\text { Ref } \\
0.894,21.739\end{array}$ & $\begin{array}{l}\text { Ref } \\
1.099\end{array}$ & $\begin{array}{l}\text { Ref } \\
0.100,12.048\end{array}$ \\
\hline Hypertension & $\begin{array}{l}\text { No } \\
\text { Yes }\end{array}$ & $\begin{array}{l}\text { Ref } \\
1.416\end{array}$ & $\begin{array}{l}\text { Ref } \\
0.457,4.386\end{array}$ & $\begin{array}{l}\text { Ref } \\
0.617\end{array}$ & $\begin{array}{l}\text { Ref } \\
0.118,3.215\end{array}$ \\
\hline Diabetes mellitus & $\begin{array}{l}\text { No } \\
\text { Yes }\end{array}$ & $\begin{array}{l}\text { Ref } \\
1.736\end{array}$ & $\begin{array}{l}\text { Ref } \\
0.508,5.952\end{array}$ & $\begin{array}{l}\text { Ref } \\
1.239\end{array}$ & $\begin{array}{l}\text { Ref } \\
0.168,9.174\end{array}$ \\
\hline
\end{tabular}

Note: ${ }^{\mathrm{a}} \mathrm{p}$-value $<0.05$.

Abbreviations: $\mathrm{OR}$, odds ratio; $\mathrm{Cl}$, confidence interval; COPD, chronic obstructive pulmonary disease.

regional differences among practices covered by the nationwide database. Future studies that link clinical information with claims data and evaluate cost-effectiveness for different mitigation efforts to reduce the burden on the health system can inform ways to reduce the actual burden of COVID-19 and further improve the effectiveness of health care system responses.

\section{Conclusions}

In conclusion, based on national insurance claims data representing the 9 days after the epidemic peak of COVID-19, we found that prudent arrangements of ICU beds must be made to facilitate the mechanical ventilation needs of critically ill patients in regions where containment strategies with admission and isolation policies are implemented.

\section{Abbreviations}

COVID-19, coronavirus disease; CFR, case fatality rate; NHIS, National Health Insurance System; HIRA, Health
Insurance Review \& Assessment Service; DM: diabetes mellitus; COPD, chronic obstructive pulmonary disease; ICD-10, International Classification of Diseases, 10th Revision; CT, computed tomography; aOR, adjusted odds ratio; $95 \% \mathrm{CI}, 95 \%$ confidence interval.

\section{Data Sharing Statement}

The datasets used during the current study are available from the corresponding author on a reasonable request.

\section{Ethics Approval and Consent to Participate}

This study was approved by the Kyung Hee University Institute Research Board (KHSIRB-20-164). Informed consent was not required because this study used deidentified, open (publicly available) data.

\section{Acknowledgments}

The authors appreciate healthcare professionals dedicated to treating COVID-19 patients in Korea, and the Ministry 
of Health and Welfare and the Health Insurance Review \& Assessment Service of Korea for sharing invaluable national health insurance claims data in a prompt manner.

\section{Author Contributions}

All authors made a significant contribution to the work. $\mathrm{I}-\mathrm{H} \mathrm{Oh}$ and $\mathrm{SH}$ Lee took part in the conception, study design and drafting. J. -Y Seon took part in the acquisition and analysis of data. H. -Y Kim, N. Thakkar and P. Selvaraj performed model analysis and provision. A. Bershteyn, H. -Y Kim, J. -S Park, J. -H Park, N. Thakkar, P. Selvaraj, S. -Y Park, S. -I Nam and W. $\mathrm{H}$ Jeon carried out critical revision. All authors gave final approval of the version submitted have agreed on the journal to which the article has been submitted, and agree to be accountable for all aspects of the work.

\section{Funding}

This study was supported by a grant from the Korean Health Technology R\&D Project through the Korea Health Industry Development Institute (KHIDI), funded by the Ministry of Health and Welfare, Republic of Korea (No. HI18C0446). The funding body had no role in the design of the study and collection, analysis, and interpretation of data and in writing of the manuscript.

\section{Disclosure}

The authors declare that they have no competing interests.

\section{References}

1. WHO. Coronavirus disease (COVID-2019) situation report-98.

2. Jason Oke CH. Global COVID-19 case fatality rates. Oxford COVID19 Evidence Service. 2020. Available from: https://www.cebm.net/ covid-19/global-covid-19-case-fatality-rates/. Accessed March 19, 2020.

3. European Centre for Disease Prevention and Control. Daily risk assessment on COVID-19. 2020.

4. Qiu $\mathrm{H}$, Tong $\mathrm{Z}$, Ma $\mathrm{P}$, et al. Intensive care during the coronavirus epidemic. Intensive Care Med. 2020;46(4):576-578. doi:10.1007/ s00134-020-05966-y

5. Central Disaster Management Headquarters. Cases in Korea by City/ Province; Coronavirus Disease-19, Republic of Korea. 2020. Available from: http://ncov.mohw.go.kr/en/bdBoardList.do?brdId= $16 \&$ brdGubun $=162 \&$ dataGubun $=\&$ ncvContSeq $=\&$ contSeq $=\&$ board $\mathrm{id}=\&$ gubun $=$. Accessed October 5, 2020.

6. Korean Society of Pediatric Infectious Diseases, Korean Society of Epidemiology, Korean Society for Antimicrobial Therapy, Korean Society for Healthcare-associated Infection Control and Prevention, and Korea Centers for Disease Control and Prevention. Report on the epidemiological features of coronavirus disease 2019 (COVID-19) outbreak in the Republic of Korea from January 19 to March 2, 2020. J Korean Med Sci. 2020;35(10):e112. doi:10.3346/jkms.2020. $35 . \mathrm{e} 112$
7. Korea Centers for Disease Control and Prevention. The update of COVID-19 in Korea as of March 15. 2020. Available from: https:// www.cdc.go.kr/board/board.es?mid=a20501000000\&bid=0015. Accessed March 19, 2020.

8. Kim, S. W., Lee, K. S., Kim, K., et al. A brief telephone severity scoring system and therapeutic living centers solved acute hospitalbed shortage during the COVID-19 outbreak in Daegu, Korea. Journal of Korean Medical Science, 2020;35(15).

9. Park SY, Kim YM, Yi S, et al. Coronavirus disease outbreak in call center, South Korea. Emerg Infect Dis. 2020;26(8):1666-1670. doi:10.3201/eid2608.201274

10. Korea Centers for Disease Control \& Prevention. Coronavirus disease-19: summary of 2370 contact investigations of the first 30 cases in the Republic of Korea. Osong Public Health Res Perspect. 2020;11(2):81-84. doi:10.24171/j.phrp.2020.11.2.04

11. Hale T, Petherick A, Phillips T, Webster S Variation in government responses to blavatnik school working paper. 2020. Available from: https://en.unesco.org/inclusivepolicylab/sites/default/files/learning/docu ment/2020/4/BSG-WP-2020-031-v3.0.pdf. Accessed October 5, 2020.

12. Korea Centers for Disease Control \& Prevention. COVID-19 Response Guidelines for Local Government, 7-4 Edition (In Korean); 2020.

13. World Health Organization. Clinical Management of Severe Acute Respiratory Infection (SARI) When COVID-19 Disease is Suspected. World Helath Oragnization; 2020. Available from: https://www.who. int/docs/default-source/coronaviruse/clinical-management-of-novelcov.pdf. Accessed April13, 2020.

14. Lee YR, Cho B, Jo MW, et al. Measuring the economic burden of disease and injury in Korea, 2015. J Korean Med Sci. 2019;34(Suppl 1):e80. doi: $10.3346 / \mathrm{jkms} .2019 .34 . \mathrm{e} 80$

15. Kim HJ, Lee GH, Ryoo S, et al. Role of confirmatory interferon-gamma release assays in school outbreaks of tuberculosis in South Korea. Int J Tuberc Lung Dis. 2015;19(5):576-581. doi:10.5588/ijtld.14.0636

16. Service HIRA. opendata4COVID19. Helath Insurance Review \& Assessment Service; 2020.

17. Thakkar N, Klein DJ, Selvaraj P, Famulare M. COVID in New York City: A Model-Based Perspective. Available from https://covid.idmod. org/data/COVID_Modeling_NYC.pdf. Accessed April 21, 2020.

18. Daegu disaser managemnt Headquater. COVID-19 daily briefing in Daegu metropolitan City. 2020. Available from: http://www.daegu.go.kr/ dgcontent/index.do?menu_id=00936590. Accessed October 5, 2020.

19. Comprehensive situation dashboard in National Emergency Department Information System 2020. 2020. Available from: http:// portal.nemc.or.kr/medi_info/dashboards/dash_total_emer_org popup_for_egen.do. Accessed April 13, 2020.

20. Lauer SA, Grantz KH, Bi Q, et al. The incubation period of coronavirus disease 2019 (COVID-19) from publicly reported confirmed cases: estimation and application. Ann Intern Med. 2020;172 (9):577-582. doi:10.7326/M20-0504

21. Korea Centers for Disease Control and Prevention. Coronavirus disease-19: the first 7755 cases in the Republic of Korea. Osong Public Health Res Perspect. 2020;11(2):85-90. doi:10.24171/j. phrp.2020.11.2.05

22. Han P-I, Diao K-Y, Pang T, Huang S, Yang Z-G. Comparison of clinical features between critically and non-critically ill patients in SARS and COVID-19: a systematic review and meta-analysis. Lancet Glob Health. 2020.

23. Kim M-Y, Kim S-H, Lee J-H, et al.. COVID-19 National Emergency Response Center, Epidemiology Center, Epidemiology \& and Case management team Weekly report on the COVID-19 situation in the Republic of Korea (As of March 28, 2020). Public Health Wkly Rep. 2020;13(14):792-806.

24. Organization for Economic Co-operation and Development (OECD). OECD Health Statistics 2019. 2019 Organisation for Economic Cooperation and Development; 2020. 
25. COVID-19 National Emergency Response Center, Epidemiology \& Case Management Team, Korea Centers for Disease Control \& Prevention. Contact transmission of COVID-19 in South Korea: novel investigation techniques for tracing contacts. Osong Public Health Res Perspect. 2020;11(1):60-63. doi:10.24171/j.phrp.2020.11.1.09

26. Liao X, Wang B, Kang Y. Novel coronavirus infection during the 2019-2020 epidemic: preparing intensive care units-the experience in Sichuan Province, China. Intensive Care Med. 2020;46(2):357-360. doi:10.1007/s00134-020-05954-2
27. Guan WJ, Ni ZY, Hu Y, et al. Clinical characteristics of coronavirus disease 2019 in China. $N$ Engl J Med. 2020;382:1708-1720. doi:10.1056/NEJMoa2002032

28. Zhou F, Yu T, Du R, et al. Clinical course and risk factors for mortality of adult inpatients with COVID-19 in Wuhan, China: a retrospective cohort study. Lancet. 2020;395(10229):1054-1062. doi:10.1016/S0140-6736(20)30566-3

\section{Publish your work in this journal}

Risk Management and Healthcare Policy is an international, peerreviewed, open access journal focusing on all aspects of public health, policy, and preventative measures to promote good health and improve morbidity and mortality in the population. The journal welcomes submitted papers covering original research, basic science, clinical \& epidemiological studies, reviews and evaluations, guidelines, expert opinion and commentary, case reports and extended reports. The manuscript management system is completely online and includes a very quick and fair peer-review system, which is all easy to use. Visit http://www.dovepress.com/testimonials.php to read real quotes from published authors.

Submit your manuscript here: https://www.dovepress.com/risk-management-and-healthcare-policy-journal 